\title{
A extrafiscalidade como instrumento de controle do impacto ambiental gerado pelos resíduos sólidos diante da globalização do mercado*
}

\author{
Extra-fiscality as a control instrument of the environmental impact generated by \\ solid waste before market globalization
}

\author{
Fernando Joaquim Ferreira Maia** \\ Rafaela Patrícia Inocêncio da Silva ${ }^{\star * \star}$
}

\section{Resumo}

A globalização representa um fenômeno amplo com implicações distintas de acordo com o ponto de vista observado. A partir da leitura do livro "Globalização: um mapa dos problemas", de Danilo Zolo, busca-se dar mais visibilidade à globalização em suas nuances relacionadas às questões ambientais, principalmente no que se refere aos resíduos provenientes dos bens consumidos. Logo, é preciso fazer uma releitura da globalização, pois, se acabar com esta é impossível, da mesma forma também não é viável uma solução que acabe com os resíduos sólidos. Dessa maneira, não basta somente discutir como diminuir a geração dos resíduos, é crucial desenvolver mecanismos para estimular essas ações. Uma ferramenta em nível nacional que se apresenta nessa empreitada é a Lei $n^{0}$ 12.305/2010 (PNRS), pois em seu art. $8^{\circ}$, inciso IX, elenca instrumentos de "incentivos fiscais, financeiros e creditícios" para tentar amenizar os problemas decorrentes dos resíduos sólidos. O método de pesquisa escolhido foi o dedutivo, a técnica de pesquisa empregada foi a documentação por meio indireto. Além disso, também se fez uso da pesquisa bibliográfica. A conclusão que se chegou ao final deste trabalho é de que a extrafiscalidade representa um mecanismo apto a reduzir a quantidade dos resíduos sólidos e, por consequência, reduzir os danos da globalização ao meio ambiente decorrente do aumento de resíduos, oriundo do consumo exagerado.

Palavras-chave: Globalização. Meio ambiente. Resíduos sólidos.

\section{Abstract}

Globalization represents a broad phenomenon that has distinct implications according to the observed point of view. From the reading of the book Globalization: a map of problems, by Danilo Zolo, it will give more visibility to globalization in its nuances related to environmental issues, especially with regard to waste from the consumed goods. Therefore, it is necessary to re-read globalization, because ending it is impossible, just as it is also not feasible a solution that will eliminate solid waste. In this way, it is not enough to discuss how to reduce the generation of these wastes, it is crucial to develop mechanisms to stimulate these actions. One tool at a national level that is presented in this work is Law No. 12,305 / 2010 (PNRS), because in its art. 8, item IX, it lists fiscal, financial and credit incentive instruments that can be used to try to mitigate problems arising from solid waste. The research method chosen was the deductive, the research technique employed was documentation through indirect means. We also made use of bibliographic research. The conclusion reached at the end of this work is that the extrafiscality represents a mechanism able to reduce the amount of solid waste and, consequently, reduce the damages of the globalization to the environment due to the increase of residues, coming from the exaggerated consumption.

Keywords: Globalization. Environment. Solid waste.

Este artigo é fruto do apoio do CNPq/PPGCJ/UFPB para o estudo desenvolvido, mediante bolsa de estudos, no Programa de Pós-Graduação em Ciências Jurídicas da Universidade Federal da Paraíba, e parte das discussões da dissertação de mestrado desenvolvida.

Professor Adjunto III da Universidade Federal Rural de Pernambuco. Professor Permanente do Programa de Pós-Graduação em Ciências Jurídicas da Universidade Federal da Paraíba-PPGCJ/UFPB. Professor Colaborador do Programa de Pós-Graduação em Educação, Culturas e Identidades-PPGECI-UFRPE/FUNDAJ. Possui Doutorado e Mestrado em Direito pela Universidade Federal de Pernambuco, Especialização em Direito Processual Civil pela mesma Universidade e Graduação em Direito pela Universidade Católica de Pernambuco. Tem experiência na área de Direito, atuando nas áreas de Direito Ambiental e Agrário, Direitos Humanos, Retórica Jurídica e Teoria e Filosofia do Direito e História do Direito. Recife-PE-Brasil. E-mail: fernandojoaquimmaia@gmail.com.

*.*. Mestra em Direito pelo Programa de Pós-Graduação em Ciências Jurídicas pela UFPB. Integrante do Grupo de Pesquisa CNPq "Saberes Ambientais - Homenagem a Enrique Leff: Sustentabilidade, Impacto, Gestão e Direitos". João Pessoa-PB-Brasil. E-mail: rafaelainocencio@hotmail.com. 


\section{Introdução}

Todos os modelos econômicos existentes basearam-se na apropriação dos recursos naturais para atender às necessidades do ser humano. O ciclo clássico da economia sempre compreendeu o meio ambiente como uma fonte infinita de recursos naturais, onde se busca exclusivamente o aproveitamento imediato, o que ocasionou diferentes alterações ambientais e também na qualidade de vida da sociedade.

Neste contexto, surgiu a globalização, que representa um fenômeno amplo com implicações distintas de acordo com o ponto de vista observado. O artigo fundamenta-se no livro de Danilo Zolo (2010), "Globalização: um mapa dos problemas", para dar mais visibilidade à globalização em suas nuances relacionadas às questões ambientais; não que os demais pontos sejam menos relevantes, mas tenta relacionar seus escritos ao impasse a respeito do que fazer com os resíduos provenientes dos bens consumidos.

Uma dificuldade atual quanto à análise das relações globais é a busca por meios que harmonizem a tutela ambiental e o crescimento da economia. Por conseguinte, conciliar esses conceitos se mostra indispensável para a concepção mais recente de desenvolvimento sustentável.

Em sua obra, Zolo (2010, p. 24) diz que é possível reverter o quadro do planeta, contudo é necessário abandonar o estilo liberal-consumista e envolver as formas de produção e de comércio mundial.

O consumismo é um dos frutos da globalização. Ele torna a sociedade moderna refém ao ser influenciada pelo crescimento econômico e pela abundância de bens e serviços disponíveis. Diante da gama de bens produzidos, no entanto, não se observa um adequado tratamento despendido aos resíduos gerados pelo consumo demasiado, o que acaba resultando em resíduos sólidos em quantidade cada vez mais elevadas e com qualidades ainda mais complexas.

Assim, a temática dos resíduos sólidos merece ser debatida. Conforme pesquisa elaborada pelo Instituto de Pesquisa Econômica Aplicada (IPEA, 2016), no intuito de fundamentar o Plano Nacional de Resíduos Sólidos, entre os anos de 2000 e 2008, a quantidade de resíduos sólidos enviadas para destinação final cresceu em média 35\% em relação à pesquisa anterior (BRASIL, 2011).

É preciso fazer uma releitura da globalização, fenômeno fruto do impacto da revolução tecnológica no campo da comunicação e que repercute na circulação de mercadorias e na produção dos resíduos sólidos. Isto porque, à medida que o mercado consumidor cresceu nos últimos tempos, aumentou também a produção de resíduos. Assim, o ponto de partida para chegar a uma solução está na forma de tratar e desestimular o descarte de bens.

Não basta somente discutir como diminuir a geração dos resíduos sólidos. É fundamental desenvolver mecanismos para estimular ações redutoras do seu impacto no meio ambiente. Uma ferramenta em nível nacional que se apresenta nessa empreitada é a Lei $n^{\circ}$ 12.305/2010 (PNRS), pois em seu art. $8^{\circ}$, inciso IX, elenca instrumentos de "incentivos fiscais, financeiros e creditícios" para tentar amenizar os problemas decorrentes dos resíduos sólidos. Ao se considerar os instrumentos econômicos existentes para a proteção do meio ambiente, deve-se visualizar o tributo e sua função extrafiscal como uma valiosa ferramenta de indução de ações a serem realizadas.

Assim, tem-se por objeto de estudo o aumento da produção dos resíduos sólidos como um dos problemas ambientais oriundos da globalização. Recorreu-se à contribuição de Danilo Zolo, pois o autor apresenta um enfoque interessante para se tratar da globalização.

O artigo partirá de considerações sobre a globalização. Em seguida, apresentam-se as relações que a globalização tem com os problemas ambientais e, principalmente, com o aumento dos resíduos sólidos. No terceiro momento, mostra-se como a aplicação da extrafiscalidade pode ser um caminho para minimizar os danos ambientais oriundos do aumento de resíduos. Os instrumentos de pesquisa, basicamente, foram livros, sites e periódicos relativos à temática da globalização com o Direito Ambiental. Diversas fontes foram utilizadas como suporte, principalmente o texto da Constituição Federal de 1988 e a legislação infraconstitucional tributária e ambiental. 
Por fim, ao se considerar as questões anteriormente apontadas, o trabalho apresenta os seguintes questionamentos: Como se pode reverter o quadro danoso de aumento da produção dos resíduos sólidos largamente influenciados pelo processo de globalização do consumo? Neste sentido, como é possível minimizar as problemáticas ambientais decorrentes dos resíduos por meio de medidas tributárias que favoreçam práticas ambientalmente adequadas e desestimulem atividades que não dão o adequado tratamento a estes?

\section{Implicações da tutela jurídica ambiental na ordem econômica}

A desejada concretização do Estado Social e Democrático de Direito necessita de um olhar diferenciado sobre cada ramo jurídico. Esta concretização acaba passando também pela proteção ao meio ambiente, que, por sua vez, é primordial para se alcançar um desenvolvimento econômico e social. A cultura do cuidar dirigido ao ambiente não é só voltada ao desenvolvimento; zelar pelo lugar em que se vive é, antes de tudo, algo essencial à continuidade da vida humana.

Mesmo estando associado à ideia de desenvolvimento, o meio ambiente só apareceu na pauta de discussões, nas mais diferentes regiões do globo, no final dos anos 60 . A principal razão do início dessas discussões foi o aparecimento dos primeiros sinais de degradação ambiental, como o superaquecimento do planeta e os primeiros sinais de escassez de alguns recursos naturais.

A partir daí, os bens naturais tiveram suas características particulares apontadas e passaram a ser entendidos como objetos que ensejam tutela jurídica. $O$ meio ambiente, atualmente, desponta como bem público de uso comum do povo, verdadeiro direito difuso fundamental no alcance do direito à vida. $\mathrm{A}$ Convenção da ONU sobre Ambiente e Desenvolvimento, realizada em Estocolmo, Suécia, no ano de 1972, por meio de seu artigo $n^{\circ} 2$, deu respaldo jurídico ao meio ambiente como um elemento essencial para o direito à vida. Este artigo assim dispõe: "2. A proteção e o melhoramento do meio ambiente humano é uma questão fundamental que afeta o bem-estar dos povos e o desenvolvimento econômico do mundo inteiro, um desejo urgente dos povos de todo o mundo e um dever de todos os governos."

Depois da conferência realizada em Estocolmo, as legislações de vários países passaram a tratar da matéria ambiental em seus ordenamentos jurídicos. Quanto à ampliação do número de legislações que tratam da matéria relativa ao meio ambiente, Guerra (2007, p. 3) assim escreve:

Para se ter a ideia da proliferação de documentos internacionais em matéria ambiental após 1972, até os anos 60, existiam apenas alguns dispositivos para a proteção dos pássaros úteis à agricultura, a proteção das peles de focas e sobre a proteção das águas. De 1960 até 1992, foram criados mais de 30.000 dispositivos jurídicos sobre o meio ambiente, entre os quais 300 tratados multilaterais e 900 acordos bilaterais, tratando da conservação e mais de 200 textos oriundos das organizações internacionais.

Como se pode perceber, a preocupação com o ambiente justifica-se, visto que as necessidades humanas são inúmeras enquanto os recursos naturais são limitados. Logo, o meio ambiente é um valor a ser protegido de forma autônoma em relação aos demais institutos jurídicos, a fim de garantir que esse bem seja usufruído pelas presentes e futuras gerações. Neste cenário, o Estado passa a ter por objetivo executar uma política que seja capaz de gerar um desenvolvimento sustentável, conciliando desenvolvimento econômico e social, além de repercutir diretamente na qualidade de vida das pessoas. Steigleder (2011, p. 79) esclarece outras peculiaridades inerentes ao meio ambiente:

[...] e esse parece ser o principal fundamento para a autonomia do meio ambiente, o que conduz para a autonomia jurídica do dano ambiental, que se caracterizará pela lesão ao bem jurídico imaterial, autônomo em relação aos bens corpóreos que o integram, estes sim suscetíveis a regimes de apropriação.

No tocante ao arcabouço jurídico brasileiro, o país também seguiu na linha de legislar para assegurar a tutela ambiental. De acordo com o art. 225 da Constituição Federal de 1988, a proteção e a defesa 
ambientais são deveres da sociedade e do Estado, pelo qual ambos devem agir para promoção da vida, para presentes e futuras gerações.

O mesmo art. 225, em seu parágrafo $1^{\circ}$, indica os deveres do Poder Público, sendo que essas obrigações são intituladas de deveres especiais. Por seu turno, os parágrafos $2^{\circ}$ e $3^{\circ}$ do mesmo artigo apresentam algumas obrigações imputadas a toda a comunidade quando há um dano ambiental. A Constituição Federal é, por conseguinte, clara ao afirmar que a proteção do meio ambiente não é somente um dever do Estado, mas também obrigação de toda a sociedade.

Ainda na perspectiva da ordem jurídica nacional, o art. 170 da Constituição Federal de 1988 prevê os outros princípios que tratam da ordem econômica. Dentre eles, há o inciso VI, que preceitua o princípio da defesa do meio ambiente, inclusive mediante tratamento diferenciado, conforme o impacto ambiental gerado por todos os produtos, serviços e seus processos de elaboração e de prestação. Quanto a essa previsão, interessa acentuar a vontade do constituinte originário em fomentar as atividades econômicas que estejam concatenadas com os padrões de defesa ambiental.

Conforme o art. 174 da Constituição de 1988, a atuação do Estado na economia deve ser feita de forma normativa e reguladora, isto é, limitando-se às funções de fiscalização, de incentivo e de planejamento. Estas são determinantes para o setor público. Já para a iniciativa privada, têm caráter apenas indicativo. O agir estatal pautado em ações é, nas palavras de Eros Grau (2012), o que configura a Constituição Dirigente com nuances econômicas.

Isto posto, é possível perceber que os dispositivos normativos anteriormente especificados visam conciliar o desenvolvimento econômico, a defesa social e a tutela ambiental. A matéria econômica é inseparável da proteção do meio ambiente, não se mostrando, assim, elementos contraditórios e que se excluem. Ao contrário, são elementos que podem e devem se consolidar mutuamente.

\section{Os danos ambientais decorrentes do processo de globalização}

Os danos oriundos da globalização são demasiados, sobretudo os de caráter ambiental. Nesse sentido, Zolo (2010, p. 14) inicia sua exposição apontando que as falhas correlatas à globalização são gerais e atuais atingindo todo o planeta. Admite que, por ser esta uma problemática de dimensão global, não é possível apontar uma única intervenção capaz de resolvê-la. Assim, pode-se afirmar que Zolo não seria um apologista ou um crítico da globalização, mas um intermediário entre esses dois pontos.

O processo de globalização não é recente, todavia alguns estudiosos têm opiniões diametralmente diferentes quanto ao seu surgimento, desenvolvimento e expectativas. Algo que é, de certa forma, unânime entre os estudiosos deste tema, contudo, é a extensão que esse processo é capaz de atingir. A globalização é um fenômeno amplo e apresenta implicações distintas conforme a área estudada.

Na tendência de se classificar a globalização, ela foi associada à revolução tecnológica, que representa uma ferramenta importante para conectar pessoas. Uma das pretensões do autor é tentar definir o que é o processo de globalização, sendo que, para isso, ele utiliza o fator de ampliação das relações sociais. Logo, para Zolo (2010, p. 15), globalização é: "[...] um processo de extensão 'global' das relações sociais entre os seres humanos, tão amplo a ser capaz de cobrir o espaço territorial e demográfico de todo o planeta. $O$ termo se difundiu em sincronia com uma fase de aceleração dos fenômenos de integração econômico-social."

Ao apresentar seu conceito de globalização, abre-se espaço para contrapor definições distintas, levantadas por outros grandes estudiosos. Dentre as definições que Zolo cita, um conceito que chama a atenção é o desenvolvido por Luciano Gallino (2010, p. 15). Para este sociólogo, a globalização é o processo de universalismo do mercado. Logo, um fenômeno estruturalmente com fins econômicos.

Em meio a essa polissemia que tenta conceituar globalização, há ainda a divisão de dois grandes grupos que tentam definir os seus principais aspectos: são os chamados apologistas, que apontam seus pontos positivos, e os críticos ao fenômeno, que indicam as falhas que esse processo tem e os resultados 
que geram. Os críticos da globalização ficam encarregados de denunciar a concentração de riqueza, as inconstâncias dos mercados financeiros, o uso desordenado das reservas naturais e hídricas, os conflitos armados e a desnutrição, entre outras questões.

Além disso, os críticos ainda apontam que a globalização tem levado a uma degradação ecológica com dimensões mundiais. A globalização é associada ao efeito estufa; à destruição da camada de ozônio; à poluição do ar; às mudanças químicas dos oceanos; à desertificação; à acidez dos solos e dos lençóis freáticos; à contaminação dos rios, dos mares e dos lagos; à perda da diversidade biológica; ao uso demasiado dos bens naturais renováveis e dos não-renováveis; à poluição dos mares dos pólos; à devastação das matas; ao acúmulo das emissões tóxicas e lixo; além do declínio da qualidade de vida nos centros urbanos, da difusão rápida de novas doenças e da escassez de trabalho. Destaque-se que a responsabilidade por esse desastre antes ficava por conta dos países desenvolvidos, tendo em vista seu alto grau de industrialização, mas ocorre que o processo de produção, que aperfeiçoa os ganhos em detrimento dos cuidados ambientais, ganhou outros adeptos, como os países em desenvolvimento. Assim, conforme Zolo (2010, p. 24), é possível reverter o quadro instalado, contudo é necessário abandonar o estilo liberal-consumista e envolver novas formas de produção e de comércio mundial.

Zolo (2010, p. 24) apresenta uma posição menos influente em números de adeptos, mas guarda um pensamento moderado quando comparado com posições apologistas e críticas. Nesta posição, entende-se que a globalização é algo novo e complexo, e que guarda efeitos positivos e negativos. Entretanto, os efeitos positivos são deixados em segundo plano por aqueles que mais se beneficiam com relações globalizadas. $O$ problema reside em deixar a globalização ser regida unicamente pelo mercado e pelas tecnologias. Zolo (2010, p. 31) fala ainda da economia globalizada nos seguintes termos:

Não nos encontramos na presença de uma simples intensificação e ampliação das relações econômicas internacionais. A economia contemporânea se caracteriza claramente como uma 'economia global': nesta, os principais fatores de produção apresentam uma taxa de interdependência, de integração e de abertura que não encontra precedentes na história da humanidade.

Essa globalização traz benefícios, como a redução do custo da produção e, via de consequência, um aumento da produtividade. Esses dois fatores foram impulsos que ocasionaram a ampliação do consumo de bens e serviços nas últimas cinco décadas. Esses dados foram extraídos de relatórios das Nações Unidas aos quais Zolo (2010, p. 37) teve acesso. Também se notou que a globalização foi capaz de ampliar o PIB do planeta, e não somente para os países industriais, mas também para países que despontaram nos últimos anos como nichos de desenvolvimento econômico, a exemplo do Brasil. O autor também apontou uma ampliação da renda individual de boa parte dos habitantes do planeta.

Zolo (2010, p. 32-33) faz uma consideração específica ao tema ambiental. Dispõe ele que a tutela do meio ambiente pode ser obtida através da mediação dos mercados globais, pois, em longo prazo, a concorrência no mercado terminará por fazer prevalecer as modalidades produtivas que respeitam o equilíbrio ecológico e não são agressivas ao ambiente natural, isto é, afirmar-se-ão as práticas produtivas que demandarem um reduzido uso de matéria e um menor consumo de energia.

Existem ainda autores que destacam que um dos efeitos da globalização é a diferença de ritmo entre o desenvolvimento econômico e o desenvolvimento humano, o que culmina no aumento de diferenças internas em vez de uma integração socioeconômica do planeta. A maior dificuldade, neste caso, é que as diferenças são mais agudas em relação aos mais vulneráveis economicamente, principalmente os que vivem em países mais pobres.

Zolo (2010, p. 37) faz uso dos estudos de John Galbraith apresentados no prefácio da obra "Human development Report", das Nações Unidas. Em 1998, o consumo realizado pela população mundial se concentrava nas camadas mais abastadas, pois $20 \%$ da população mais rica consumia $86 \%$ do que era produzido. Em comparação, apenas $1,3 \%$ de todos os bens e serviços eram desfrutados pelos $20 \%$ mais pobres do mundo. Ainda se tratando do fenômeno da pobreza e de suas relações com a globalização, um 
dado diz respeito ao fato da pobreza absoluta ter se difundido em áreas consideradas agrícolas, embora sua maior concentração ainda se encontre nas periferias dos grandes centros urbanos.

Outro dado apontado pelo autor faz alusão ao poder que os grandes grupos econômicos detêm na fixação do preço dos produtos que são fabricados. Conforme apresenta Zolo (2010, p. 41), esses grupos têm a capacidade de se esquivar das imposições fiscais de cada país onde se instalam. Também escolhem a base territorial aonde vão se instalar e não se sujeitam às normas trabalhistas e à arrecadação tributária imposta. Outro aspecto que favorece o poderio dos grupos econômicos é a volatilidade de capital, sobre a qual Zolo (2010, p. 41) se manifesta da seguinte maneira: "Em uma situação na qual os capitais se movem com facilidade de um âmbito jurisdicional a um outro, se for imposta a uma empresa multinacional uma taxação mais rigorosa, acenderá a luz do exist: o capital ameaçará fugir, ou o faz sem maiores dificuldades."

Zolo (2010, p. 43) faz uso das colocações de Gallino para se manifestar quanto à competitividade dos mercados e como funcionam os seus mecanismos. Aponta que é um equívoco não se levar em consideração os custos da mão de obra de cada país e em cada área específica. Quando não se cogita sobre esses desníveis, ameaça-se a proteção social do trabalhador, a legislação de proteção ambiental, e outras proteções e proibições feitas.

Quanto à proteção do trabalho e defesa do patrimônio ambiental, a Alemanha foi uma das nações que alcançou padrões elevados, enquanto que a Indonésia só chegou a estabelecer critérios de proteção ambiental e de garantias a seus trabalhadores. Na Indonésia, o custo da mão de obra é consideravelmente baixo se comparado com países que têm padrões protecionistas. Os indonésios não têm quase nenhuma proteção trabalhista, além disso, não podem entrar em greve, pois tal conduta é vedada em lei.

Aponta Zolo que a relação entre a globalização, o desenvolvimento econômico e o desenvolvimento humano não é um problema considerado resolvido. A globalização traz um aumento absoluto da pobreza e uma crescente diferenciação entre uma minoria rica e uma maioria pobre, além do crescimento da produtividade.

Por fim, Zolo (2010, p. 15) faz menção novamente a Gallino, que estatui ser necessário reequilibrar a concorrência entre as empresas, melhorando o qualitativo do desenvolvimento econômico e promovendo um desenvolvimento local.

\section{A política nacional de resíduos sólidos (PNRS) e seus aspectos econômicos e tributários}

A sociedade moderna, influenciada pelo crescimento econômico e pela abundância de bens e serviços disponíveis, é refém do consumismo, no entanto não se observa um adequado tratamento dos resíduos gerados pelo consumo demasiado, o que acaba resultando em resíduos sólidos em quantidade cada vez mais elevada e com qualidade ainda mais complexa. Somam-se estes aspectos à falta de utilização de técnicas adequadas e ainda a ausência de recursos financeiros capazes de dar uma destinação final ambientalmente correta. Assim, é premente a necessidade de se garantir a aplicabilidade de instrumentos jurídicos eficazes na gestão dos resíduos.

No contexto do desenvolvimento econômico sustentável e visando criar um conjunto de princípios, objetivos e instrumentos para uma gestão integrada dos resíduos sólidos, foi elaborada, em 02 de agosto de 2010, a Lei $n^{\circ} 12.305$, depois de quase 20 anos de discussões. Coube à nova legislação instituir a Política Nacional dos Resíduos Sólidos (PNRS), sendo "um marco inovador e ousado na implementação da gestão compartilhada do meio ambiente, propugnada pelo art. 225 da Constituição Federal" (YOSHIDA, 2014, p. 3). A referida lei tem guarida no artigo 24, VI e VIII, da Constituição de 1988 e elenca princípios e instrumentos para uma gestão adequada dos resíduos sólidos.

A lei que instituiu a Política Nacional de Resíduos Sólidos também tratou de definir resíduos sólidos. A definição é apresentada por meio do inciso XVI do art. $3^{\circ}$ que assim determina: 
XVI - resíduos sólidos: material, substância, objeto ou bem descartado resultante de atividades humanas em sociedade, a cuja destinação final se procede, se propõe proceder ou se está obrigado a proceder, nos estados sólido ou semissólido, bem como gases contidos em recipientes e líquidos cujas particularidades tornem inviável o seu lançamento na rede pública de esgotos ou em corpos d'água, ou exijam para isso soluções técnica ou economicamente inviáveis em face da melhor tecnologia disponível; [...].

O artigo 13 da lei que instituiu a PNRS apresenta a classificação quanto à origem e quanto à periculosidade dos resíduos sólidos. Essa divisão ocorre porque alguns resíduos produzidos podem ocasionar problemas ao meio ambiente e, consequentemente, ao homem. Logo, a possibilidade de degradação ambiental e os riscos que esta gera devem ser observados pelo viés econômico.

Partindo-se dessa premissa, de que os danos ao ecossistema devem ser visualizados pela seara econômica, os geradores de resíduos, principalmente os que desempenham atividades de cunho lucrativo, devem desenvolver práticas que passem pela responsabilidade com a destinação adequada dos resíduos e também dos rejeitos produzidos. No caso dos resíduos sólidos, devem-se buscar meios que sejam capazes de gerar sua reciclagem ou sua reutilização.

Como o consumo da população aumentou consideravelmente nos últimos tempos, é descabida a ideia de acabar com geração de resíduos sólidos que a sociedade produz diuturnamente. Neste aspecto, a PNRS não deixou a desejar, uma vez que apontou que o caminho a ser seguido é uma gestão adequada dos resíduos sólidos, para o que a utilização de tecnologias pode ser um pontapé inicial. Por meio de seu art. $8^{\circ}$, mais precisamente nos incisos VI e VII, a PNRS prevê a aplicação de meios tecnológicos e da pesquisa cientifica, ambos voltados para o tratamento correto de resíduos sólidos e dos rejeitos. A seguir cita-se $o$ art. $8^{\circ}$ da PNRS e alguns desses instrumentos:

Art. $8^{\circ}$ São instrumentos da Política Nacional de Resíduos Sólidos, entre outros:

$[\ldots]$

VI - a cooperação técnica e financeira entre os setores público e privado para o desenvolvimento de pesquisas de novos produtos, métodos, processos e tecnologias de gestão, reciclagem, reutilização, tratamento de resíduos e disposição final ambientalmente adequada de rejeitos;

VII - a pesquisa científica e tecnológica;

$[\ldots]$

IX - os incentivos fiscais, financeiros e creditícios;

$[\ldots]$

O Estado tem papel fundamental na utilização de tais instrumentos, pois caberá a ele a criação de meios econômicos que dêem suporte a um desenvolvimento sustentável, além de "instituir medidas indutoras às condutas de preservação e redução da geração de resíduos sólidos no processo produtivo" (BARREIRA, 2014, p. 145).

Aragão (2006, p. 79) sustenta que as definições da PNRS foram vistas com receio na doutrina, ao passo que estimularam a jurisprudência e provocaram os legisladores e os operadores econômicos. Assegurou que os resíduos são objetos corpóreos, apropriáveis e desinteressantes para seu detentor.

A Lei $n^{\circ} 12.305 / 2010$ traz em seu art. $8^{\circ}$, inciso IX, como parte de seus instrumentos, "os incentivos fiscais, financeiros e creditícios". Essas hipóteses devem ser utilizadas em favor de todos os agentes, sejam eles públicos, sejam particulares, que se adequarem às suas proposições.

No que diz respeito à concessão de incentivos, a Lei no 12.305/2010 também estabeleceu a possibilidade em razão da pessoa e das peculiaridades próprias de cada ente. Como aduz Sidney Guerra (2012, p.180), coube ao legislador permitir e conceder os incentivos a outros setores da economia:

[...] o legislador também permitiu a concessão de incentivos para os seguintes segmentos: a) indústrias e entidades dedicadas à reutilização, ao tratamento e à reciclagem de resíduos sólidos produzidos no território nacional; b) projetos relacionados à responsabilidade pelo ciclo de vida dos produtos, prioritariamente em parceria com cooperativas ou outras formas de associação de catadores 
de materiais reutilizáveis e recicláveis formadas por pessoas físicas de baixa renda; c) empresas dedicadas à limpeza urbana e atividades relacionadas. As hipóteses acima dão conta dos incentivos fiscais e financeiros. Já os casos especiais em que sejam necessários incentivos creditícios, as instituições financeiras federais poderão criar linhas especiais de financiamento para cooperativas, associações de catadores, atividades voltadas para a reutilização e/ou reciclagem de resíduos sólidos e para projetos de investimentos em gerenciamento de resíduos sólidos oriundos dos beneficiários do Sistema Financeiro Nacional, sendo estes para investimentos produtivos.

No tocante aos contornos que esses incentivos fiscais podem ter na Política Nacional de Resíduos Sólidos, deve-se chamar a atenção para o fato de que, a depender da atuação da atividade econômica a ser incentivada, várias espécies tributárias podem ganhar esses benefícios. Empresas que têm a maior parte de suas atividades ligadas à tributação pelo ICMS poderiam ser desoneradas de tais tributos. Essa mesma desoneração pode ser aplicada ao se tratar do ISS, do IPI, dentre outras espécies tributárias (PACOBAHYBA; BELCHIOR, 2012, p. 340).

À luz da PRNS foram criadas obrigações tanto para as pessoas físicas quanto jurídicas, de direito público ou privado, que produzam direta ou indiretamente resíduos sólidos. Assim, a cadeia de produção passou a ter novos fatores econômicos, o que refletiu na tributação dessas atividades. Na cadeia produtiva dos resíduos, podem ser incluídos vários tributos, notadamente os impostos indiretos, que incidem sobre bens e serviços, como o ICMS, ISS e IPI.

Quando se tem em mente a obrigação estatal de proteção ao meio ambiente, deve-se também lembrar do papel que tem a tributação. Esta concepção se coaduna com o exposto por Nora Beatriz Lifschitz (2014, p. 283) ao comentar que "los problemas ambientales tienes sus respuestas o soluciones em el Derecho Ambiental, la Econimía y el Derecho Financiero y Tributario". Além disso, não se deve perder de vista que o tributo é essencial para arrecadar os recursos monetários que posteriormente serão aplicados na concretização dos mais variados interesses sociais.

A extrafiscalidade, concebida aqui como a escolha de mecanismos de natureza econômica para a realização da política de preservação ambiental, tem no tributo um relevante instrumento de atuação. Verifica-se a necessidade de atrelar a tributação à questão ambiental, pois o tributo é responsável por custear os interesses públicos, ao passo que a preservação do ambiente ecologicamente equilibrado se configura como um direito fundamental assegurado. Eis o ensinamento de Roberto Feraz (2009, p. 23) referente ao tributo e à sua relação com a natureza: "O tributo é instrumento de proteção ao meio ambiente quando serve para internalizar custos ambientais que estavam externos à atividade, isto é, quando exprimem o custo da atividade tendente a eliminar os efeitos nocivos ao meio ambiente causados por uma atividade econômica lícita."

Ainda tratando dessa relação, apresenta-se a lição descrita por Simoni Martins Sebastião (2011, p. 228):

[...] tributos e meio ambiente têm, então, entre si, uma relação de correspondência no que concerne à própria atividade financeira do Estado, ou seja, na administração das receitas e despesas. Aqui, em especial, nas despesas relativas à prevenção, conservação e restauração do meio ambiente, chama o Estado também o particular a participar na concretização de seu dever público, de ordem constitucional, colaborando não só através de comportamentos ecologicamente corretos, mas também proporcionando o numerário necessário ao cumprimento do desiderato.

Nusdeo (2012) e Cavalcante (2014) defendem que incentivos fiscais devem ser concedidos às atividades econômicas que se adéquam à tutela do meio ambiente. A defesa dessa concepção está amparada mediante o princípio do protetor-recebedor, visto que a desoneração parcial ou total da carga tributária se configura como uma sanção premial aos contribuintes. Observa-se que o sistema jurídico passa a absorver com mais tenacidade a ideia da sanção premial, tão difundida por Norberto Bobbio (2007), e que almeja estimular as atitudes desejadas, dentre as quais, os comportamentos ambientalmente adequados.

Assim, ao se considerar os instrumentos econômicos existentes para a proteção do meio ambiente, deve-se visualizar o tributo e a sua função extrafiscal como uma valiosa ferramenta de indução de ações a 
serem realizadas pelo Estado enquanto agente normativo e regulador, principalmente no que se relaciona à aplicabilidade da lei que disciplina a matéria dos resíduos sólidos.

\section{Como resolver o impasse existente entra a globalização e produção de resíduos sólidos mediante a tributação ambiental?}

Segundo as lições de Zolo (2010), a globalização contribuiu para o desenvolvimento mundial em muitas áreas, mas é um processo que apresenta falhas. Ao se falar em globalização e no aumento dos resíduos sólidos, deve-se rememorar o papel de destaque que tiveram as revoluções tecnológicas nessa relação. Isto porque elas afetaram consideravelmente o crescimento das produções e a circulação de mercadorias, culminando em uma maior quantidade de resíduos.

Desta monta, é perfeitamente cabível aplicar a visão do sociólogo Enrique Leff (2006, p. 241) quando se objetiva dar novos rumos à globalização se pautando na tutela ao meio ambiente:

A resolução dos problemas ambientais, assim como a possibilidade de incorporar condições ecológicas e bases de sustentabilidade aos processos econômicos [...] e para construir uma racionalidade ambiental e um estilo alternativo de desenvolvimento, implica a ativação de um conjunto de processos sociais; a incorporação dos valores do ambiente na ética individual, nos direitos humanos e nas normas jurídicas que orientam e sancionam o comportamento dos atores econômicos e sociais [...].

Leff (2009, p. 184) dispõe sobre a necessidade de alterar a forma como a globalização é guiada. Afirma que:

Contudo, os mecanismos de mercado são insuficientes para gerar as condições de crescimento econômico sustentável sem a intervenção do Estado e estes agentes juntos são incapazes de assegurar o bem-estar das maiorias e uma distribuição equitativa da riqueza, sem a participação direta da sociedade na gestão dos recursos produtivos.

Os problemas decorrentes da globalização vão desde questões sobre a regulamentação do mercado de trabalho até alterações ambientais. O consumismo é um dos frutos da globalização e torna refém a sociedade moderna, que é influenciada pelo crescimento econômico e pela abundância de bens e serviços disponíveis. No entanto, diante da gama de bens produzidos, não se observa um adequado tratamento aos resíduos gerados pelo consumo demasiado, o que acaba resultando em resíduos sólidos em quantidade cada vez mais elevadas e com qualidades ainda mais complexas.

Quanto à ausência de tratamento aos resíduos gerados pelo consumo exacerbado, assim aduzem Belinda Cunha et al. (2015, p. 38):

A atual (ir)racionalidade econômica mantém um sistema produtivo inconsequente, 'manipulando até mesmo a aquisição dos chamados 'bens de consumo duráveis' que necessariamente são lançados ao lixo (ou enviados a gigantescos ferros-velhos, como os 'cemitérios de automóveis' etc.), muito antes de esgotada sua vida útil'.

É indubitável que a globalização correlaciona-se a diversas áreas, mas a economia é um dos setores que mais se beneficiou com os meios globalizados. Para o sociólogo Luciano Gallino (2010, p. 15), globalização é o processo de universalismo do mercado, portanto um fenômeno estruturalmente com fins econômicos. Assim, percorrendo o caminho que trata da globalização sob sua perspectiva econômica, adentra-se na produção de mercadorias, pois dois ramos que mais ganharam com o alargamento dos mercados foram a produção e a circulação de bens e serviços.

Todavia, atrelado ao aumento de circulação de bens e serviços, também cresce a produção de resíduos, pois quando há consumo, algo resta, e esse resíduo deve ter um tratamento correto. Mas não é só isso. Muitos dos processos produtivos não aplicam em seus sistemas produtivos técnicas que protejam os bens ambientais. Ao invés disso, usam indiscriminadamente recursos naturais pagando valores irrisórios, sem falar dos desastres ambientais que diuturnamente ocorrem. 
Zolo (2010, p. 32-33) defende que a proteção ao meio ambiente passa pela mediação dos mercados globais, pois, no decurso do tempo, a concorrência terminará por fazer uma escolha pelas modalidades produtivas que respeitem o equilíbrio ecológico e não sejam agressivas ao ambiente natural, isto é, estimularse-ão aquelas atividades produtivas que demandarem uma reduzida manipulação de matéria e um menor consumo de energia. Em relação a esse pensamento, Leff (2009, p. 246) não é tão otimista:

[...] a economia (a racionalidade econômica, o processo econômico) precisa de flexibilidade e maleabilidade para se ajustar Às condições de sustentabilidade ecológica; o debate político se fortaleceu com as descobertas da ciência sobre a crescente insustentabilidade do planeta e os riscos ecológicos que a ameaçam, mas não conseguiu se separar das razões de força maior do mercado.

Outro dado apontado por Zolo (2010) faz alusão ao poder que os grandes grupos econômicos detêm na fixação do preço dos produtos que são fabricados. Como já dito, esses grupos têm a capacidade de se esquivar das imposições fiscais nos países onde se instalam. Também escolhem a base territorial em que vão se instalar e não se sujeitam às normas trabalhistas e à arrecadação tributária imposta, Isso ocorre pelo fato de os capitais se moverem com facilidade de um país a outro. Logo, se for imposta a uma empresa multinacional uma taxação mais rigorosa, o capital ameaçará fugir ou o fará sem maiores dificuldades.

Desta maneira, não basta somente discutir como diminuir a geração dos resíduos sólidos. É crucial desenvolver mecanismos para estimular essas ações. Uma ferramenta em nível nacional que se apresenta é a Lei $n^{\circ}$ 12.305/2010 (PNRS), pois em seu art. $8^{\circ}$, inciso IX, elenca instrumentos de "incentivos fiscais, financeiros e creditícios" para tentar amenizar os problemas decorrentes dos resíduos sólidos.

No que diz respeito à concessão de incentivos, a Lei $n^{\circ}$ 12.305/2010 também estabeleceu a possibilidade em razão da pessoa e das peculiaridades próprias de cada ente. No tocante aos contornos que os incentivos fiscais podem ter na Política Nacional de Resíduos Sólidos, deve-se chamar a atenção para o fato de que, a depender da atuação da atividade econômica a ser incentivada ou desestimulada, várias espécies tributárias podem ganhar esses benefícios, ou terem uma tributação mais onerosa no intuito de obrigar a cuidar dos seus resíduos.

À luz da PRNS, foram criadas obrigações tanto para pessoas físicas quanto jurídicas, de direito público ou privado, que produzam direta ou indiretamente resíduos sólidos. Assim, a cadeia de produção passou a ter novos fatores econômicos, o que refletiu na tributação dessas atividades. Podem ser incluídos vários tributos na cadeia produtiva dos resíduos, notadamente os impostos indiretos, que incidem sobre bens e serviços, como o ICMS, ISS e IPI. A incidência dessas espécies tributárias pode ser utilizada para desencorajar a larga produção de resíduos, ou agir para incentivar que os bens resultantes do consumo não agridam o meio ambiente. Desta maneira, é possível cogitar, a título de exemplo, uma majoração do ICMS quando o bem produzido não apresentar um plano de gerenciamento que faça com que seu produtor tenha que dar o descarte final aos seus resíduos. Nesta linha de raciocínio, também se pode imaginar uma isenção de taxas ambientais quando os resíduos do bem consumido sejam biodegradáveis ou dirigidos para reciclagem. Assim, a extrafiscalidade tem no tributo um relevante instrumento de atuação.

Ao se considerar os instrumentos econômicos existentes para a proteção do meio ambiente e, sobremodo no que se refere aos resíduos sólidos, deve-se visualizar no tributo e sua função extrafiscal como uma valiosa ferramenta de indução de ações a serem realizadas pelo Estado enquanto agente normativo e regulador. Logo, medidas tributárias que atuem para incitar o gerenciamento correto dos resíduos devem ser implementadas, ao passo que uma tributação mais onerosa deve ser destinada às atividades que não apresentam uma preocupação com os resíduos que resultam do consumo de seus bens. Atuações nesse sentido são valiosas ferramentas para diminuir os danos que o aumento e a periculosidade que os resíduos têm ocasionado.

\section{Conclusão}

O artigo mostrou os efeitos do processo de globalização e como ele contribuiu, através das revoluções tecnológicas, para o crescimento do consumo de bens e, consequentemente, dos resíduos sólidos. Além 
disso, em outro momento apontou-se o papel positivo que a tributação pode ter para diminuir, ou ao menos controlar, os problemas que os resíduos sólidos geram ao meio ambiente.

Buscou-se entender o fenômeno da globalização, que, apesar de seus aspetos positivos, também trouxe consigo efeitos danosos à tutela ambiental. O questionamento quanto aos efeitos negativos do processo de globalização nasce quando se passa a observar as problemáticas geradas pela crescente degradação ambiental, sendo que esses danos ao meio ambiente também implicam nos aspectos econômicas e repercutem, sobretudo, no campo social.

Assim, dedicou-se especial atenção a analisar como a globalização, através da revolução tecnológica, contribuiu para a expansão dos mercados consumidores. Atrelada à expansão dos mercados e do consumo de mercadorias, também houve o aumento da produção de resíduos sólidos. Sendo assim, é indispensável pensar o que fazer para minimizar a quantidade de resíduos produzidos diuturnamente. É necessário ampliar o espectro de proteção jurídica ao meio ambiente, na medida em que constitui uma evolução aos mecanismos tradicionais de política ambiental, pois pode promover a utilização adequada dos resíduos sólidos.

Chegou-se à Lei no 12.305/2010 (PNRS), a qual prevê em seu art. $8^{\circ}$, inciso IX, os instrumentos de "incentivos fiscais, financeiros e creditícios" para tentar amenizar os problemas decorrentes da produção dos resíduos sólidos. A utilização da extrafiscalidade pode ser uma ferramenta para que a natureza retome seu papel de destaque frente ao mercado consumidor, desde que devidamente utilizada.

Conforme os incentivos fiscais e extrafiscais aplicados à matéria de resíduos sólidos, deve-se chamar a atenção para o fato de que, a depender da atuação da atividade econômica a ser incentivada, várias espécies tributárias podem ser utilizadas com a concessão de benefícios. Logo, empresas que têm a maior parte de suas atividades ligadas à tributação pelo ICMS, podem ser desoneradas de tais tributos. Essa mesma desoneração pode ser aplicada ao se tratar do ISS, do IPI, dentre outras espécies tributárias que podem ser desoneradas consoante o ramo da atividade empresarial. Destaca-se que tais benefícios tributários somente devem ser concedidos se houver um cuidado com os resíduos que são gerados, ou seja, se os mesmos não são poluentes, se depois de descartados são enviados à reciclagem ou se têm o destino final adequado.

A perspectiva de melhoria nos padrões de atuação na proteção ambiental, apontada pela Lei $n^{\circ}$ 12.305/2010, acaba concorrendo de forma decisiva para a construção de novos paradigmas ambientais, aptos a auxiliar na solução da aparente contradição ainda persistente de promoção do desenvolvimento econômico com a necessidade de proteger os recursos naturais. Essa promoção do desenvolvimento econômico pode ocorrer por meio da racionalização do processo produtivo, do reaproveitamento de matérias-primas, especialmente não renováveis, da destinação adequada dos resíduos oriundos da atividade econômica, dentre outras opções. Com isso, há uma consequente economia de recursos, economia de energia e postergação da poluição gerada, bem como mitigação das desigualdades sociais. Além disso, a referida legislação aponta que os instrumentos tributários podem ter sua aplicabilidade voltada aos resíduos sólidos. Logo, se essa tributação for implementada adequadamente, culminará na tutela ambiental, de forma a diminuir os danos que a globalização do consumo gera.

Por tudo isso que se comentou até aqui, pode-se concluir que a extrafiscalidade enquanto um instrumento fiscal à disposição do mercado representa um mecanismo apto a cuidar do destino e tratamento correto dos resíduos sólidos. Agindo com foco na redução da quantidade dos resíduos sólidos também se estarão reduzindo, por consequência, os danos ao meio ambiente, principalmente quanto ao efeito da globalização que ocasionou o aumento da produção de resíduos, fruto do consumo exagerado.

\section{Referências}

ARAGÃO, Maria Alexandra de Sousa. O princípio do nível elevado de proteção e a renovação ecológica do direito do ambiente e dos resíduos. Coimbra: Almedina, 2006. 
BARREIRA, Fábio Nieves. Aspectos tributários. In: JARDIM, Arnaldo; YOSHIDA, Consuelo; MACHADO FILHO, José Valverde. Política Nacional, Gestão e Gerenciamento de Resíduos Sólidos. Barueri: Manole, 2014. p. 133-164

BOBBIO, Norberto. Da estrutura à função: novos estudos de teoria do direito. São Paulo: Manole, 2007.

BRASIL. Constituição (1988). Constituição da República Federativa do Brasil. Brasília, DF, Senado, 1988. Disponível em: <http://www.planalto.gov.br/ccivil_03/constituicao/constituicaocompilado.htm>. Acesso em: 03 jan. 2017.

BRASIL. Lei $\mathbf{n}^{\mathbf{0}} \mathbf{1 2 . 3 0 5}$, de 2 de agosto de 2010. Institui a Política Nacional de Resíduos Sólidos; altera a Lei $\mathrm{n}$-9.605, de 12 de fevereiro de 1998; e dá outras providências. Disponível em: <http://www.planalto. gov.br/ccivil_03/_ato2007-2010/2010/lei//12305.htm>. Acesso em: 08 fev. 2017.

CAVALCANTE, Denise Lucena (Coord.). Tributação ambiental: reflexos na Política Nacional de Resíduos Sólidos. Curitiba: CRV, 2014.

CUNHA, Belinda Pereira da et al. Enrique Leff: da ordem simbólica à dialética social para a sustentabilidade. Disponível em: <https://www.ucs.br/site/midia/arquivos/saberes_ambientais_ebook. pdf>. Acesso em: 29 set. 2016.

FERRAZ, Roberto. Instrumentos econômicos de proteção ao meio ambiente: o art. 36 da Lei 9.985/00. In: SCAFF, Fernando Facury; ATHIAS, Jorge Alex. Direito tributário e econômico aplicado ao meio ambiente e à mineração. São Paulo: Quartier Latin, 2009. p. 328-349.

GRAU, Eros. A ordem econômica da Constituição de 1988. 15. ed. São Paulo: Malheiros, 2012.

GUERRA, Sidney. Direito internacional ambiental: breve reflexão. Revista Direitos Fundamentais e Democracia, Curitiba, v. 2, p. 1-11, 2007. Disponível em: <http://revistaeletronicardfd.unibrasil.com.br/ index.php/rdfd/article/view/191/183>. Acesso em: 30 ago. 2016.

GUERRA, Sidney. Resíduos sólidos: comentários à Lei 12.305/2010. Rio de Janeiro: Forense, 2012.

BRASIL. Ministério do Meio Ambiente. Plano nacional de Resíduos Sólidos. Versão preliminar para consulta pública. Brasília, 2011. Disponível em: <http://www.sinir.gov.br/documents/10180/185386/253 publicacao02022012041757.pdf/d18a7f4f-c2a3-4eef-a05c-286bfcbce7ea>. Acesso em: 30 ago. 2016.

LEFF, Enrique. Ecologia, capital e cultura: a territorialização da racionalidade ambiental. Petrópolis: Vozes, 2009.

LEFF, Enrique. Racionalidade ambiental: a reapropriação social da natureza. Rio de Janeiro: Civilização Brasileira, 2006.

LIFSCHITZ, Nora Beatriz. Fiscalidad ambiental para el desarrollo sustentable a la luz de la economia verde. In: AMARAL, Paulo Adyr Dias do; LEVATE, Luiz Gustavo (Org.). Extrafiscalidade ambiental e desenvolvimento sustentável. Belo Horizonte: D’ Plácido, 2014. p. 281-294.

NUSDEO, Ana Maria de Oliveira. Pagamento por serviços ambientais: sustentabilidade e disciplina jurídica. São Paulo: Atlas, 2012.

ORGANIZAÇÃO DAS NAÇÕES UNIDAS (ONU). In: CONFERÊNCIA DAS NAÇÕES UNIDAS SOBRE O MEIO AMBIENTE HUMANO, Estocolmo, 05-16 jun. 1973. Disponível em: <www.mma.gov.br/ estruturas/agenda21/_arquivos/estocolmo.doc>. Acesso em: 02 fev. 2017.

PACOBAHYBA, Fernanda Mara de Oliveira Macedo Carneiro; BELCHIOR, Germana Parente Neiva. A concessão de incentivos fiscais como instrumento da Política Nacional de Resíduos Sólidos: uma possibilidade aberta à discussão. Disponível em: <http://www.publicadireito.com.br/publicacao/uff.php>. Acesso em: 10 fev. 2016.

SEBASTIÃO, Simone Martins. Tributo ambiental. Curitiba: Juruá, 2011.

STEIGLEDER, Annelise Monteiro. Responsabilidade civil ambiental: as dimensões do dano ambiental no direito brasileiro. 2. ed. rev. atual. e ampl. Porto Alegre: Livraria do Advogado, 2011. 
YOSHIDA, Consuelo. Competência e as diretrizes da PNRS: conflito e critérios de harmonização entre as demais legislações e normas. In: JARDIM, Arnaldo; YOSHIDA, Consuelo; MACHADO FILHO, José Valverde. Política nacional, gestão e gerenciamento de resíduos sólidos. Barueri: Manole, 2014. p. 3-38.

ZOLO, Danilo. Globalização: um mapa dos problemas. Florianópolis: Conceito, 2010.

Recebido em: 30/04/2017

Aprovado em: 11/07/2018 